\title{
Soil origin and plant genotype structure distinct microbiome compartments in the model legume Medicago truncatula
}

\section{Shawn P. Brown}

University of Memphis

Michael A. Grillo

Loyola University Chicago

Justin C. Podowski

University of Chicago

Katy Denise Heath ( $\square$ kheath@illinois.edu )

University of Illinois at Urbana-Champaign https://orcid.org/0000-0002-6368-744X

\section{Research}

Keywords: common garden, evolution, genetic variation, mutualism, nodule microbiome

Posted Date: April 12th, 2020

DOI: https://doi.org/10.21203/rs.3.rs-21175/v1

License: (a) (i) This work is licensed under a Creative Commons Attribution 4.0 International License.

Read Full License

Version of Record: A version of this preprint was published at Microbiome on September 28th, 2020. See the published version at https://doi.org/10.1186/s40168-020-00915-9. 


\section{Abstract}

Background: Understanding the genetic and environmental factors that structure plant microbiomes is necessary for leveraging these interactions to address critical needs in agriculture, conservation, and sustainability. Legumes, which form root nodule symbioses with nitrogen-fixing rhizobia, have served as model plants for understanding the genetics and evolution of beneficial plant-microbe interactions for decades, and thus have added value as models of plant-microbiome interactions. Here we use a common garden experiment with 16S rRNA gene amplicon and shotgun metagenomic sequencing to study the drivers of microbiome diversity and composition in three genotypes of the model legume Medicago truncatula grown in two native soil communities.

Results: Bacterial diversity decreased between external (rhizosphere) and internal plant compartments (root endosphere, nodule endosphere, and leaf endosphere). Community composition was shaped by strong compartment $x$ soil origin and compartment $x$ plant genotype interactions, driven by significant soil origin effects in the rhizosphere and significant plant genotype effects in the root endosphere. Nevertheless all compartments were dominated by Ensifer, the genus of rhizobia that forms root nodule symbiosis with $\mathrm{M}$. truncatula, and additional shotgun metagenomic sequencing suggests that the nodulating Ensifer were not genetically distinguishable from those elsewhere in the plant. We also identify a handful of OTUs that are common in nodule tissues, which are likely colonized from the root endosphere.

Conclusions: Our results demonstrate strong host filtering effects, with rhizospheres driven by soil origin and internal plant compartments driven by host genetics, and identify several key nodule-inhabiting taxa that coexist with rhizobia in the native range. Our results set the stage for future functional genetic experiments aimed at expanding our pairwise understanding of legume-rhizobium symbiosis towards a more mechanistic understanding of plant microbiomes.

\section{Background}

Plants grow in close co-association with a striking diversity of microorganisms [1]. These microbes, including bacteria, archaea, fungi, and protists, can inhabit every conceivable plant organ and tissue as either epiphytes or endophytes. A rapidly growing body of literature has documented the influence that the microbiome can have on critical plant traits including disease resistance [2-5], nutrient acquisition and growth [6-9], abiotic stress tolerance [10,11], and flowering phenology [12, 13]. Thus, the microbiome can be viewed as an extended phenotype of the plant genome that can enhance the ability of plants to cope with environmental stressors [1, 10,14-16]. A fuller understanding of plant microbiomes is critical for improvements in environmental sustainability [17], agriculture [18], and conservation [19]. To leverage microbiomes to address critical needs, we must better understand the factors that structure microbial communities within and among plant hosts, building a predictive understanding of microbiome assembly. 
The advent of modern sequencing technology has provided a renaissance for microbial ecology by allowing for rigorous characterization of microbial communities and their relationships with macrobial hosts [20]. Some authors have even suggested that the hologenome, comprised of the host's genome and all genomic content of associated microbes, is a unit of biological organization driving ecological and evolutionary processes [21, 22]. Microbiomes are diverse and have been found to vary across plant species [23-25], within species among different genotypes [26-30], and among plants grown in different environments [29, 31-33]. Additionally, distinct compartments within a plant (e.g., phyllosphere, rhizosphere, endosphere) often vary in microbiome composition $[1,29,33]$. Thus, environmental and genetic factors working together largely determine plant microbiome assembly.

Soil communities can vary considerably in space and time, leading to variation in the microbial pool available for colonization [34, 35]. For roots, a two-step model for microbiome colonization has been proposed [1,33], wherein root exudates initially drive a shift in community composition in the soil directly influenced by the root (i.e., the rhizosphere), followed by plant genetic factors that regulate entry inside the root (i.e., the root endosphere). The acquisition of the leaf microbiome (i.e., phyllosphere) is less wellunderstood, but likely depends on similar multi-level processes $[36,37]$. In order to gain entry into the endosphere (interior of the leaves, roots, stem, etc.), microbes must overcome plant innate immunity [38]. The field of community genetics has long-held that intraspecific genetic variation, and thus intraspecific evolution, can scale up to influence community and ecosystem-level processes [39]. In plants, substantial genetic variation is maintained for plant immune response machinery [40], and numerous other ecologically-relevant phenotypes; thus, it is perhaps not surprising that host genotypes vary in microbiome composition [24, 28, 29, 33]. Yet many microbiome studies have focused on only a single genotype; therefore, studies using multiple genotypes and wild species are necessary to better resolve the role of host plant genotypes in structuring the microbiome, particularly since domesticated species may be inferior in their ability to regulate microbiomes when compared to wild relatives [41-43].

Leveraging existing knowledge in well-studied models for plant-microbe interactions can help us better understand the factors structuring plant microbiomes. Leguminous plants (Fabaceae) are one of the most diverse lineages (ca. 20,000 spp.), and legumes are the second most important crop family behind grasses [44]. For decades, legumes have served as important model systems for understanding the genetics, ecology, and evolution of plant-microbe interactions because they form intimate symbioses both with nodulating nitrogen-fixing bacteria (rhizobia) and with arbuscular mycorrhizal fungi (AMF). Decades of molecular genetic work have uncovered numerous genes that are required for symbiosis with these key symbionts [45-47], and a subset of these so-called 'symbiosis genes' have been implicated in interactions between legumes and a diversity of microorganisms beyond rhizobia and AMF [48-50]. Zgadzaj et al., [51], for example, detected a shift in microbiome community composition in mutant Lotus japonicus that were defective in nodulation, compared to wild type plants. This line of inquiry suggests that core symbiosis genetic pathways can influence interactions with a broad range of microbes beyond the model symbiosis in which they were discovered, and thus that models for plant-microbe symbiosis have added value in understanding plant microbiomes. 
Microbial communities can be strongly structured by plant compartments, and this is potentially the case for legume nodules. Nodules represent a truly distinct environment from the adjacent root endosphere by being: 1) low in oxygen, which is necessary for nitrogen fixation [52, 53], 2) rich in both carbon and nitrogen [54], and 3) dominated by single microbial taxon (i.e., rhizobia). Thus the nodule may harbor microbes that are specialists of this unique environment; however, this hypothesis has not been tested. Limited evidence in AMF supports this notion by demonstrating that communities differ between the root and the nodule, but are more similar between nodules of different legume species, suggesting that there may indeed be nodule AMF specialists [55]. Furthermore, the origin of nodule microbial communities is uncertain; bacteria could migrate into nodules from within roots, or there could be directed colonization from the rhizosphere. Culturing initiatives have revealed a diverse group of non-rhizobial species housed in nodules, and several of these bacteria can act to increase nodulation as well as overall plant growth (reviewed by [56]). In fact, commercially available inocula often include both rhizobia and non-rhizobial strains for this reason [57]. The mechanisms for enhanced nodulation and/or plant performance are unknown, but likely involve microbe-microbe interactions which could manifest inside the nodule or in other plant compartments. Interestingly, non-rhizobial members of nodule microbiomes can even possess nodulation and/or nitrogen fixation genes [56]. A rigorous characterization of nodule microbiomes that is not limited by culture bias is necessary to determine if specialist taxa exist in this unique compartment, and potentially shed light on functional interactions and mechanisms.

The model legume Medicago truncatula (hereafter Medicago), a winter annual native to the Mediterranean basin [58], has been used extensively to discover the genetic pathways necessary for establishment and ongoing symbiotic trade in both the rhizobium and AMF symbiosis [45, 59-61]. Despite its prominence in plant-microbe interactions, however, no studies have presented a thorough characterization of the Medicago microbiome grown in native soil, so to date we have an incomplete picture of the microbiome of this species beyond its interaction with Ensifer rhizobia. Here we first grow three Medicago genotypes from natural populations in each of two native soils in a common garden experiment to ask: 1) To what extent do plant genotype and soil origin structure the microbiome? 2) Do plant compartments (rhizosphere, root endosphere, nodule endosphere, phyllosphere) harbor distinct microbiomes, and how are these affected by plant genotype and soil origin? 3) Are there specialist microbial taxa in the nodule, and how is this community assembled (i.e., from the rhizosphere or root endosphere)? Next we perform an additional inoculation experiment, adding one of four Ensifer strains to ask: 4) Does genetic variation in rhizobia influence the broader microbiome, and in what compartments? Finally, we use additional shotgun metagenomic sequencing of a subset of root, nodule, and leaf samples to explore the genetic variation in Ensifer bacteria throughout the plant.

\section{Results}

Sequencing results - 16S rRNA amplicon sequencing: After all sequence quality control, OTU demarcations, and removal of rare OTUs, we retained 3180 OTUs for the plant genotype $x$ soil experiment and 1650 OTUs for the rhizobium genotype experiment. A detailed sample $x$ OTU table is provided in 
Table S1, and OTU abundances across the sampling design with associated taxonomy, biomarker results, and representative sequences are available in Table S2.

Sequencing results - shotgun metagenomic sequencing - After quality control, on average 41 million paired end reads per sample were retained. After removing read pairs that mapped to the Medicago reference, root endosphere samples contained on average six million read pairs and nodule samples contained 34 million read pairs. On average, $25 \%$ of the remaining reads successfully mapped to the reference (E. medicae WSM419) in root endosphere samples, versus $90 \%$ in nodule samples. Root endophyte samples with a high percentage of reads mapped to $E$. medicae WSM419 produced more than 30 scaffolds ranging from $50 \mathrm{~kb}$ to $427 \mathrm{~kb}$, while nodule samples regularly produced 40 or more scaffolds greater than $50 \mathrm{~kb}$, and each nodule sample produced more than 15 scaffolds greater than $100 \mathrm{~kb}$.

Plant genotype $x$ soil experiment. Several results suggest that compartment was the major force structuring the microbiome of Medicago plants. First, PVCA indicated that interactions with compartment explained the largest amount of variance in bacterial community composition (compartment $x$ soil source: $23 \%$, and compartment x plant genotype: $6 \%$; Table 1), indicating that soil origin and plant genotype both influenced community composition, but that these effects depended on compartment. Main effects of plant genotype, soil origin, compartment, as well as the soil origin $\mathrm{x}$ plant genotype interaction accounted for an additional $1.2-3.2 \%$ of the variation in bacterial composition each $(\sim 10.9 \%$ total; Table 1). ANOVAs on diversity estimators (diversity, evenness, and richness) indicated that compartment was the only significant effect (Table 1), with rhizospheres having the most rich, diverse, and even bacterial communities (Fig. 1a). We found no evidence for overall differences in diversity estimates among plant genotypes or between soil sources (Table 1).

To unpack the interactions indicated in the PVCA, we next used PerMANOVAs to test for the effects of soil source and plant genotype on the composition of bacterial communities within each compartment separately. Rhizospheric communities were distinct between soils originating from mainland France vs. Corsica (Table 2, Figure S1, Figure S2), but this legacy of soil origin was lost in internal plant compartments (Table 2). Instead, bacterial communities within roots responded to plant genotype (Table 2, Fig. 2), though genotype was not significant for nodule or leaf compartments (Table 2).

Bacterial communities were quite distinct across the four compartments (Table 1; Fig. 1b); only 327 (10\%) of OTUs were shared across all compartments (Figure S1). The genus Ensifer, which contains the primary $\mathrm{N}$-fixing rhizobia that form root nodule symbiosis with Medicago, was the most abundant in all compartments, though it reached higher abundances in internal plant compartments (particularly in the nodule, unsurprisingly, where it comprised $\sim 85 \%$ of reads; Fig. 1 b). Consistent with the diversity results, the rhizosphere compartment had the most (772) unique OTUs (Figure S1), and LEfSe analyses identified 313 biomarker OTUs for the rhizosphere, of wide-ranging taxonomic identities (see Table S2), some of which were common (Fig. 3b). Prominent shifts occurred in the abundances of other OTUs across internal plant compartments, including Halomonas (increased in root and leaf endospheres compared to 
nodules; Fig. 3a), and Pseudomonas (increased in leaves relative to root and nodule; Fig. 3c). Our LEfSe analyses identified 10 biomarker OTUs for leaves, dominated by Pseudomonas, Niastella and the cyanobacteria Phormidium and 12 biomarker OTUs for roots dominated by Thioalkalibacter, Neorhizobium, and Ohtaekwangia, plus one OTU (Ensifer) for nodules (Table S2).

Examination of nodule core communities identified 15 OTUs that were found in $>50 \%$ of nodule samples, including some of the most overall abundant OTUs (Table S3). Common nodule taxa included other putative $\mathrm{N}$-fixing or plant growth promoting bacterial (PGPB) members of the Rhizobiales and Burkholderiales (including several Ensifer as well as Rhizobium, Bradyrhizobium, and Rhizobacter). Besides Ensifer (OTU1), only one other OTU was found in $100 \%$ of sampled nodules - OTU4, best identified as Shewanella (Order Alteromonadales). Our $\beta_{\mathrm{RC}}$ analyses of community similarity suggest that nodule communities were much more similar to, and likely deterministically derived from, root communities (70\% significant $\beta_{\mathrm{RC}}$ values between paired samples; all significant values of $\beta_{\mathrm{RC}}$ were < -0.95 , indicating deterministic establishment) rather than rhizosphere communities $\left(26.6 \%\right.$ significant $\beta_{\mathrm{RC}}$ values) from the same plant (Fisher Exact Test, $P=0.0017$ ), and that this difference persisted independent of genotype and soil origin (all $P>0.1$ ).

Despite a strong effect of host genotype on root communities (Table 2), our LEfSe analysis found no OTUs as biomarkers for particular plant genotypes, indicating that these community differences were largely driven by shifting OTU abundance ratios rather than the exclusion of specific taxa. Interestingly, however, when we compared the dissimilarity between root and rhizosphere bacterial communities across the three plant genotypes, root and rhizosphere communities were more alike in plant genotype G96 compared to G1 (Fig. 2b), potentially suggesting that this host genotype G96 is a less stringent "filter" of external bacteria.

Rhizobium genotype experiment: In stark contrast to the plant genotype $\mathrm{x}$ soil experiment, the rhizobium genotype experiment did not yield any differences in diversity estimates across rhizobium strains $(P>$ 0.30 for strain for richness, diversity, and evenness) or rhizobium strain $x$ compartment interactions $(P>$ 0.4 for all estimators; Table S4). Compartments did differ, however, with the rhizosphere having higher richness $(P<0.001)$, diversity $(P=0.002)$, and evenness $(P=0.021)$ in ANOVA analyses (Table S4).

Further, rhizobium strain did not impact communities in PerMANOVA tests for the rhizosphere $\left(\mathrm{F}_{3,14}=\right.$ $1.08, P=0.23)$, root $\left(F_{3,15}=0.97, P=0.48\right)$, or leaf endosphere $\left(F_{3,11}=0.94, P=0.57\right)$.

Minimum Entropy Decomposition of Ensifer (OTU1): Of the four demarcated MED nodes within Ensifer (Table S5), representing within-OTU variation, only two were common (Node 3 and Node 6; comprising $84.89 \%$ and $15.02 \%$ of total node counts, respectively). The proportions of these two MED nodes found in plants differed between France and Corsica $\left(\chi^{2}=3775.6, \mathrm{P}<0.001\right)$. Plants grown in Corsican soils had higher Node 3 occurrences ( $87.5 \%$ vs. $79.9 \%$ in French soil), and reduced Node 6 occurrence $(12.4 \%$ vs. $20.6 \%$ in French soil), and these differences were consistent across each of the four plant compartments (Leaf: $\chi^{2}=2601.9, \mathrm{P}=0.001$; Nodule: $\chi^{2}=5647, \mathrm{P}<0.001$; Root: $\chi^{2}=16842$, $\mathrm{P}<0.001$; Rhizosphere: $\chi^{2}=$ $12460, P<0.001)$. Interestingly, Medicago genotype affected the proportion of Ensifer MED nodes in each 
compartment (Leaf: $\chi^{2}=3591.9, \mathrm{P}<0.001$; Nodule: $\chi^{2}=4412, \mathrm{P}<0.001$; Root: $\chi^{2}=8958, \mathrm{P}<0.001$; Rhizosphere: $\left.\chi^{2}=5994.7, \mathrm{P}<0.001\right)$, suggesting that plant genotypes were differentially colonized by Ensifer variants; however, the pattern differed across compartments. Plant genotype G96 contained a smaller proportion of Ensifer MED node 3 in nodules and roots, relative to the two other host genotypes (nodules $-78.5 \%$ in G96 vs. $90.2 \%$ and $90.3 \%$ in G1 and G27, respectively; root $-60.1 \%$ in G96 vs. $99.8 \%$ and $87.1 \%$ in $\mathrm{G} 1$ and $\mathrm{G} 27$, respectively), but actually had more node 3 in rhizosphere samples (99.9\% in G96 vs. $65.2 \%$ and $64.9 \%$ in G1 and G27, respectively). Within leaves, however, G27 and G96 were similar (>99\% MED node 3), while G1 contained a smaller proportion of Node 3 ( $83.3 \%$ node $3,16.6 \%$ node 6 ). This indicates that Ensifer MED Node membership within plants is driven by soil origin and host genotype, but patterns are generally consistent independent of plant compartments.

Metagenomic sequencing: Because Ensifer was the dominant taxon in all compartments, and MED analysis at the 16S rRNA gene indicated minimal diversity within Ensifer OTUs (see above), we used metagenomic shotgun sequencing to further examine genome-wide similarity of Ensifer populations across different compartments. Ensifer scaffolds reconstructed from root endophyte and nodule communities had, on average, $99 \%$ global sequence identity in homologous regions - suggesting that Ensifer are extremely similar throughout an individual plant. Moreover our estimate of the fraction of Ensifer cells containing each of the two symbiotic megaplasmids did not significantly differ between plant compartments $(\mathrm{W}=132, \mathrm{P}=0.10$ for pSMED01; $\mathrm{W}=151, \mathrm{P}=0.14$ for pSMED02; Fig. 4 ) - again suggesting that Ensifer are highly similar throughout the plant, including at the symbiosis megaplasmids.

\section{Discussion}

An increasing number of studies characterize plant microbiomes, moving us toward a more mechanistic and synergistic understanding of factors structuring these communities. Nevertheless, while many studies have looked at spatial variation or plant genetic variation, most studies do not simultaneously examine both soil origin and plant genotype in the same design, making direct comparisons among these effects difficult (but see [33, 62-64]). Our design, combined with sequencing microbial communities from both endosphere (root, nodule, leaf) and rhizosphere compartments, allows us to directly compare the effects of soil and genotype across these distinct "organs". Here we show that both soil origin and plant genotype contribute to microbiome composition, but that the strength of these effects depend on the compartment - whether the microbes are inside (root endosphere) or outside (rhizosphere) plant tissues. Namely, plant genotype had much stronger effects on microbes within root tissues, while soil origin had stronger effects in the rhizosphere communities. Other interesting findings include: 1) that our results mirror those of recent studies in rice [33], poplar [62], and soybean [63] identifying a similar magnitude of effects and a larger role of soil origin than plant genotype in structuring microbiome variation, particularly in the rhizosphere, 2) nodule microbiomes, while containing more than the rhizobium that fixes nitrogen in Medicago nodules (Ensifer), were much less diverse than the rest of the root endosphere, and do not appear to harbor specialist microbial taxa, and 3) Ensiferwas the dominant OTU, not only in the nodules, but throughout the entire plant. Medicago is a well-studied genetic model for plant-microbe symbiosis [60, 
$61,65]$, and ours is the first NGS study of its native soil microbiome; therefore, we anticipate that our results will be of interest to many in the plant genetics community who are interested in building on our mechanistic understanding of 2-player plant-microbe interactions to better understand plant microbiomes. We discuss the major implications of our main results below.

Soil origin influences the microbiome: Soil microbial communities are remarkably diverse [66], and serve as a source reservoir for plant colonization. Throughout the range of a plant species, soil communities can vary considerably $[67,68]$, which could potentially confer variation in microbiomes. Here we find that soil origin had a larger effect than plant genotype overall and that rhizosphere communities, in particular, responded strongly to soil source. Finding significant soil origin variation suggests that we would discover additional rhizosphere taxa if we were to sample from more locations (though less so for internalized plant microbiomes, i.e., root, nodule, leaf endospheres). This is noteworthy, as rhizosphere communities are much more diverse than internalized plant communities, and rhizosphere dynamics can have profound impacts on plant fitness (reviewed by $[1,69]$ ). Microbes are recruited to the rhizosphere by plant exudate production (reviewed by [70]). These exudates can provide a nutrient source and interact with edaphic conditions to generate a distinct environment from the surrounding soil that facilitates microbial growth, setting the stage for myriad microbe-microbe interactions that shape this dynamic community $[1,71]$. These factors, which structure the rhizosphere, depend heavily on the abiotic and biotic facets of the soil; thus it is not surprising that soil variation impacts the rhizosphere microbiome. Despite this variation in rhizosphere communities, and the fact that the rhizosphere encapsulates the roots and is the source community for endosphere colonization, internalized plant microbiomes were consistent across soils, consistent with plant genetic, cellular, and/or biochemical mechanisms that restrict entry inside plant tissues (reviewed by $[1,16]$ ).

Plant genotype structures the Medicago microbiome: Plant genetic variation played a role in structuring variation in the root endosphere community, but not in other compartments. Although we did not find that plant genotype structured rhizosphere communities, studies in other systems have identified such an effect $[33,63]$. As mentioned above, root exudates mediate the rhizosphere community assembly, and these exudates are genetically determined [71]. Examination of additional Medicago genotypes may very well reveal genetic variation for exudates which may confer rhizosphere variation, and/or nodule and leaf compartments. Importantly, growing plants in closed, bottom-watered boxes likely caused us to underestimate leaf endosphere diversity and miss key taxa; our leaf bacteria likely colonized through vertical migration via plant vasculature, whereas leaves in nature are often colonized from external sources [36, 37].

Plants in our experiment were grown in soils from the native range [58, 72]; therefore, we are likely capturing an ecologically-relevant and co-evolving set of microbes that colonize Medicago in nature. In particular, the root endosphere taxa that we sampled likely contain many of the "core" players within native Medicago plants, at least at the taxonomic scale sampled here (genus or above, see discussion below), because our results join many other studies showing that plants are robust filters of their environmental microbes $[1,73,74]$, with soil origin having little effect on internal compartments. Indeed, 
in our study, microbiome diversity decreased moving from outside to inside the plant - from the rhizosphere to the root/leaf endosphere to the nodule endosphere. This filtering, operating at the boundary between the rhizosphere and the internal tissues, is likely the result of multiple selective processes [1], and our data join others suggesting that at least some of this filtering is plant genotypedependent (see below).

Our data hint at the existence of quantitative genetic variation for niche breadth in plant microbiomes. We found that the similarity between the endosphere and rhizosphere varied among Medicago genotypes, suggesting that some genotypes might represent weaker filters than others. There is empirical evidence for variation along the specialist-generalist continuum within plant-microbe symbioses $[75,76]$, as well as among plant species, with potential applied implications for the spread of invasive legumes $[77,78]$. Using five genotypes of the plant Boechera stricta, Wagner et al. [29] found significant genetic variation for metrics of microbiome diversity. Thus while considering such variation in the broader context of niche breadth theory can help us to make sense of plant-microbe symbiosis [76], our ability to interrogate the plant genes controlling microbiome diversity alongside those controlling microbiome composition grows as plant quantitative genetics and microbiome studies come together [16].

The variation in microbial community composition that can be partitioned among plant genotypes, and thus attributed to plant genetic variation, represents the natural variation upon which selection can act in nature and also the amount of standing genetic variation available to plant breeders interested in optimizing plant-microbe interactions. Although the main effect of plant genotype was small $(\sim 1.3 \%$ of total variation), the plant genotype $x$ compartment interaction accounted for much more variation ( $6.3 \%$ ) because the effect of genotype was strong, but limited to the root endosphere compartment. These patterns generally mirror studies in other systems (e.g., $[33,62,79,80])$. The mechanisms by which plant genotype influences the microbiome are still being elucidated, but genetic studies to date suggest that plant genes related to disease resistance, cell walls, and root hair structure may contribute [81-84].

The amount of variation explained by genotype in our experiment is likely an underestimate for multiple reasons. First, we only surveyed three plant genotypes; thus, we cannot account for any genetic variants not represented in these three genotypes. Second, our 16S survey represents species- or even genus-level variation; the long history of plant-microbe symbiosis literature has shown enormous within-species genotypic variation and genotype-by-genotype interactions for infection rates and abundance [85-89]; surely this variation is also present within at least some of the taxa in the less-studied members of the plant microbiome. Indeed a recent study showed that plant genotype-dependent shifts after multiple serial passages occurred at fine taxonomic scales among closely-related OTUs [90]. We have little ability to incorporate these finer-scale genotypic effects using $16 \mathrm{~S}$ surveys of community composition, though shotgun metagenomic methods for simultaneously addressing population genetics alongside community shifts are quickly evolving (e.g., [91, 92]).

The nodule microbiome: As expected, the nodule microbiome was dominated by Ensifer, and was also inhabited by a diverse community, albeit less diverse than the surrounding root endosphere and 
rhizosphere (Fig. 1). Despite evidence that nodule communities were deterministically sampled from the root endosphere, we did not find evidence that the nodule harbors unique microbial specialists, as no OTUs were found to be biomarkers for the nodule, besides Ensifer (Table S3). Nevertheless, we did identify multiple core nodule OTUs that were abundant throughout all nodules. The occurrence of Shewanella spp. within all nodules and at great abundance is intriguing, but further experimentation is needed to investigate the potential functional roles of this taxon.

Nodules seemingly represent a distinct environment from the adjacent root endosphere, yet many OTUs are found within nodules and across other compartments. Along these lines, there are numerous examples of non-classic rhizobial species (e.g., Pseudomonas spp., Agrobacterium spp., etc.) that possess nodulation genes, nitrogen-fixation genes, or both, being cultured from nodules, suggesting that these microbes may have a specialized role in the nodule [56]. Nevertheless, culturing efforts have identified non-rhizobium species that act to increase nodulation [57]. Additional unidentified, synergistic microbes of this type likely exist, but our findings suggest they will not be strictly restricted to nodules and could be cultured from root or rhizosphere communities.

Ensifer - a major actor in the Medicago microbiome: Beyond the nodule, our results suggest an extremely dominant role for Ensifer throughout the Medicago microbiome, both inside and outside the plant. Species in Rhizobiales have been found widely in plant microbiomes, including root and leaf tissues, and from a broad diversity of plants beyond legumes (e.g., [28, 79, 80, 93, 94]). Indeed we have identified Rhizobium and Bradyrhizobium in our study, and these taxa are major members of microbiome communities in multiple compartments (Table S2), yet they do not nodulate Medicago. Recent phylogenetic reconstructions [95] and mutant screens [96] suggest that such less-specific plant associations predate the origin of root nodule symbiosis in this group. Thus nodulating rhizobia may have evolved from commensal ancestors of plant microbiomes. In many rhizobia, including Ensifer, the majority of the genes governing nodulation are contained on symbiosis plasmids [97, 98], and symbiosis genes or entire plasmids can be lost as rhizobia evolve to a commensal lifestyle [95], though this might be unlikely, at least for pSymB, which is currently considered to be a chromid (rather than conjugative plasmid) and contains at least one essential gene [98].

These past observations raised the question of whether the Ensifer OTUs in the nodule were distinct from those in other plant compartments, in terms of sequence similarity as well as genome content. Further interrogation of a subset of communities using metagenomic shotgun sequencing suggested that leaf and root endosphere Ensifer likely retain their symbiosis plasmids and thus the ability to form nodules and fix nitrogen in the future. Beyond its presence outside the nodules, however, the dominance of Ensifer was striking - reaching more than $50 \%$ OTU relative abundance (Fig. $1 \mathrm{~b}$ ) even in the leaf tissue. While microbiome studies routinely identify various rhizobium taxa, this level of prevalence among all compartments is unique. One hypothesis is that Ensiferbacteria are particularly able to colonize and proliferate in host tissues due to its long-standing beneficial symbiosis with Medicago species [99], the result of a coevolutionary process within this group and throughout the legume phylogeny, and one that appears to have led to differentiation of signaling interactions among taxa while maximizing the 
signaling recognition within taxa [100]. The ability to compete for and colonize root nodules in rhizobia is conferred by genes that act in a complex cascade of molecular "handshakes", including nod factor, exopolysaccharides, effectors, etc. (e.g., [88]; reviewed by $[46,101])$. It is possible that these molecules are used throughout the plant tissues to signal entry and allow Ensifer to proliferate in all compartments; this hypothesis could be tested by competing nod + and nod- strains of Ensifer (or other nodulation mutants) and testing their relative abundance across host compartments.

In our experiment, we did not find evidence that rhizobium genotype structured microbiome variation across endosphere compartments, or in the rhizosphere, although this question deserves further investigation. Abundant evidence exists demonstrating genetic variation for partner quality (i.e., the fitness benefits that the plant receives from interaction with a given rhizobium strain) among rhizobia genotypes $[86,87,102,103]$. Given the abundance of rhizobia within plant microbiomes (beyond the nodule), it stands to reason that they could play a pivotal role in microbe-microbe interactions and thus influence plant fitness. Indeed, nodulation mutant plants have been demonstrated to elicit distinctive shifts in microbiome composition [51]. Here we inoculated plants with individual strains of rhizobia, which is a common practice for agriculture and restoration [57]. In future experiments, one could investigate the role of rhizobium genetic variation by inoculating plants with strains that are known to be of high vs. low partner quality, or manipulate strain identity for plants with highly specific strain preference (i.e., partner choice, which is known to vary in M. truncatula; [104].

\section{Conclusions}

Here we use a manipulation in native soil to show that plant genetics and soil origin structure different compartments of the Medicago microbiome. We also found that Ensifer bacteria were abundant throughout plant tissues, where they retain symbiosis plasmids, though we do not yet know whether these symbionts are mutualistic outside the nodule. Future efforts should examine the functional roles and fitness effects of rhizobia in plant microbiomes, both above and belowground. Genetic mapping studies can uncover whether well-known legume symbiosis genes are pleiotropic, affecting interactions with Ensifer and other microbes residing throughout the plant. Leveraging plant genetics and plant breeding to improve plant health via the microbiome is a critical next step, given evidence that controlling microbial colonization through even intensive management and inoculation methods can be challenging in some conditions [105]. Finally, in this and other host-microbiome systems, integrating the vast functional variation known to exist at the strain level (genotypic variation and $G \times G$ interactions; reviewed by $[89,106])$ with microbial ecology has the potential to reveal much of the hidden heritability of the microbiome.

\section{Methods}

Overview: To study how host and symbiont genetic variation mediate the microbial communities in the rhizosphere, root endosphere, nodules, and phyllosphere of Medicago, we performed two experiments. In the "plant genotype x soil" experiment, we grew three plant genotypes in each of two soils sourced from 
the native range of Medicago to ask how the plant microbiome is structured based on plant genetic variation and what role soil origin contributed to microbiome variation. In the "rhizobium genotype" experiment, we used a single plant genotype and soil community and inoculated with one of four strains of Ensifer from two species ( 2 strains E. meliloti and 2 strains of E. medicae) to ask if plant microbiomes can be altered by rhizobium genetic variation.

Plant genotypes, rhizobium strains, and soil sources: We used three Medicago genotypes (G1, G27, G96), which were chosen based on our previous work to be differentiated at DMI1, a key symbiosis gene known to be under selection in nature $[107,108]$. The plant genotype experiment used these three Medicago genotypes, whereas only genotype (G96) was used for the rhizobium genotype experiment. Native soils collected from wild Medicago populations from mainland France $\left(43^{\circ} 08.845 \mathrm{~N}, 003^{\circ} 00.047 \mathrm{E}\right)$ and from the island of Corsica $\left(42^{\circ} 58.471 \mathrm{~N}, 009^{\circ} 21.861 \mathrm{E}\right)$ were used in these experiments. Strains of Ensifer used in the rhizobium genotype experiment were acquired from culture collections at the University of Minnesota.

Planting, inoculation, and harvest: Seeds were provided by the Institut National de la Recherche Agronomique (INRA) collection maintained at Station de Génétique et Amélioration des Plantes, INRA, Montpellier, France. For each soil treatment, native soil from either France or Corsica was added in a 1:1 ratio of field soil to sterile root wash soil media (autoclaved at $121^{\circ} \mathrm{C}$ four times for 45 minutes, alternating wet and dry cycles). Before planting, seeds were surface sterilized in dilute (5\%) bleach for five minutes, rinsed in sterile water, and cold stratified on moist filter paper for two days until seeds germinated. Seedlings were planted with native soil mixture into sterile, sealed, fully self-contained Magenta "leonard jars" to prevent cross-contamination and colonization of microbes other than those found in the native soils $[87,109]$. Magenta pots were randomly placed in a temperature controlled grow room $\left(23^{\circ} \mathrm{C}\right)$ under artificial light set to 12 hour days and randomly rearranged twice per week until harvest.

For the rhizobium genotype experiment, we inoculated three replicate plants (only G96 with only soil from mainland France) grown as above with four rhizobium strains: two Ensifer medicae (KH36b and A321) and two Ensifer meliloti (M156 and HM007-10). Strains were grown in TY media at $30^{\circ} \mathrm{C}$ and equilibrated to $\mathrm{OD}_{600}=0.5$ before pipetting $1 \mathrm{ml}$ directly on the soil at the base of the seedlings. Once inoculated, magenta pots were rearranged twice a week and grown concurrently and with the same conditions as the plant genotype $x$ soil experiment. Plants received a second inoculation as above at 16 days after planting.

Plants were harvested after seven weeks of growth. Magenta vessels were opened in a containment flow hood and plants were excised from the soil. Plants were cut at the root-shoot interface and six randomly selected leaves per plant were placed into a sterile microcentrifuge tube. Leaf tissues were washed with $1 \%$ Triton-X 100 ( $v . v)$ by vortexing and rinsing three times with ddH2O to remove any surface particles or epiphytic microbes to ensure only true endophytic microbial members remain [110]. Root tissue was rinsed in $\mathrm{ddH} 2 \mathrm{O}$ to remove loosely adhered soils. Roots were placed into sterile $50 \mathrm{~mL}$ Falcon tubes filled 
with $40 \mathrm{~mL}$ ddH2O and agitated thoroughly to remove rhizospheric soils. Next $4 \mathrm{~mL}$ of this rhizospheric soil slurry was placed into microcentrifuge tubes and pelleted [111]. These rhizospheric soils were placed directly into PowerSoil DNA Isolation Kit extraction tubes (MoBio; Carlsbad, CA, USA). Washed plant roots were placed into sterile petri dishes and all nodules were harvested and five random living nodules were placed into DNA extraction tubes. Remaining root material was cut into approximately $5 \mathrm{~cm}$ sections and six random root segments were collected (a total $30 \mathrm{~cm}$ of root tissue) and was placed a microcentrifuge tube, surface sterilized in $30 \%$ bleach for 60 seconds, and rinsed in ddH2O three times. Phyllosphere (leaf), rhizosphere, nodule and endosphere (root) tissues were placed into extraction kits (as above and stored at $-20^{\circ} \mathrm{C}$ until DNA extraction. Plants in the rhizobium genotype experiment were harvested as above.

DNA Extraction, Amplification and Sequencing: Full methods may be found in Supplemental Text S1. In brief, following extraction, bacterial communities were targeted by amplifying the V4 region of the $16 \mathrm{~S}$ rRNA gene operon as previously described [112] (Supplemental Text S1; Table S6). Samples were pooled, ligated with Illumina-specific sequencing linkers, and sequenced in one reaction of Illumina MiSeq (300PE) at the W.M Keck Center (Urbana IL, USA). Sequence data were processed as previously described using the program mothur (v.1.39.5; [113]), with modifications (see [112,114,115]).

Diversity, Communities, and Statistical Analyses: Observed OTU richness $\left(\mathrm{S}_{\mathrm{obs}}\right)$, complement of Simpson's Diversity (1-D), and Simpson's Evenness $\left(E_{D}\right)$ were estimated (1000 iterations) by subsampling 1500 sequences per sample and the average of these estimators used for downstream analysis. We used the OTU $x$ Sample table (Table S1) to generate a pairwise dissimilarity matrix (Bray-Curtis) with the above subsampling and iteration framework. We used fully factorial three-way ANOVA to test for effects of plant compartment, soil origin, or plant genotype on diversity estimators. Data were transformed to increase normality by using logit transformations (1-D and $E_{D}$ ) and Box-Cox transformations (richness) by compartment prior to analysis (Rhizosphere $\lambda=1.6$, Root $\lambda=0$, Leaf $\lambda=-0.2$, Nodule $\lambda=-0.2$ ). To investigate whether bacterial communities shifted across genotypes and soil origin, we conducted a series of oneway PerMANOVAs [116] separately for each compartment (adonis function in the R package vegan; $\mathrm{R}$ core team 2017; [117]), since initial analysis suggested that communities across plant compartment were extremely different $\left(\mathrm{F}_{3,115}=6.32, \mathrm{P}<0.001\right)$.

We visualized communities using non-metric multidimensional scaling (NMDS) as implemented in mothur using 1000 iterations (3D stress $=0.123$ ), and used axes loading scores to examine community shifts across genotypes and soil origin where PerMANOVAs were significant. To quantify the amount of bacterial community variation accounted for by each treatment and interaction, we used a modified principal variance component analysis (PVCA; $[118,119]$ ). Briefly loading scores from each of the first 10 NMDS axes (representing over $>99 \%$ variation) were used as dependent variables in random effects models using restricted maximum likelihood (REML) to determine the percentage of variation explained by each treatment, interactions, and residuals. These variance partitions were then weighted by the 
percentage of community variation explained by the NMDS axis $\left(R^{2}\right)$ (see [120]) then scaled and summed across all tested axes to total $100 \%$.

We identified biomarker OTUs that were over-represented between plant compartments, soil origins, or for genotypes within compartments using independent Linear Discriminant Analysis Effect Size (LEfSe; [121]) for each comparison. LEfSe uses Kruskal-Wallis and pairwise Wilcoxon signed rank tests, signed Linear Discriminant Analysis (LDA) log scores, and associated p-values to identify OTUs that are biomarkers for a particular treatment. Since individual plants were isolated in Magenta boxes, we also used a paired effect size approach on the 20 most abundant OTUs to test whether these taxa differed in abundance across compartments within individual plants. To calculate paired effects sizes, the differences between the relative abundance of each OTU for each compartment (within the same plant) were divided by the sum of the relative abundances. We then visualized the obtained effect size quartiles and used paired Wilcoxon-Signed Rank tests of whether OTUs differed between compartments within a plant.

To investigate the composition of nodule communities, we identified core bacterial taxa within nodules (defined as found in greater than $50 \%$ of all nodule samples) to distinguish between transient taxa that may incidentally be found in the nodules from those that may have tighter associations. To test whether nodule communities were deterministically, versus independently stochastically, structured from root or rhizosphere communities, we calculated pairwise $\beta_{R C}$ (Beta Raup-Crick) values $[122,123]$ to estimate the probability of pairwise community dissimilarity compared to null models based on data randomization. Using the program PaST (v3.12; [124]) with 1000 replicates, we calculated pairwise standardized $\beta_{\mathrm{RC}}$ values between nodule and root (or rhizosphere) communities for the same plant in a paired design as above $\left(-1 \leq \beta_{\mathrm{RC}} \leq 1\right.$, where $\left|\beta_{\mathrm{RC}}\right|>0.95$ indicates divergence from null expectation; two-tailed test, alpha=0.05). We then used Fisher's exact two-tailed tests on the number of significant paired $\beta_{\mathrm{RC}}$ values to determine whether community similarity between compartments differed between genotypes or soil origins, and whether root-nodule and rhizosphere-nodule deterministic assembly rates differed.

Further interrogating endophytic Ensifer: Because Ensifer bacteria were exceedingly common throughout all plant compartments (see Results), we examined the potential for sub-OTU variation within OTU1 (Ensifer) by first harvesting all sequences from OTUs identified as Rhizobaceae using the script mothur2oligo (http://deneflab.github.io/MicrobeMiseq), then used minimum entropy decomposition (MED; [125]) to demarcate distinct genetic groupings using Shannon entropy of obtained sequences. Representative sequences for the 17 identified nodes were then compared (BLASTn) against the representative sequences of OTU1, and MED nodes matching OTU1 at $>99 \%$ identity were retained (Table S5). This identified four Ensifernodes, two common (MED 3, MED 6) and two rare nodes (MED 101, MED 102). Next we tested whether the distributions of MED nodes differed across soil origin, genotype, or plant compartment using a series of Pearson's Chi-squared tests on node contingency tables, implemented in R (function chisq.test, p-values were simulated using 10,000 Monte Carlo replications because some cells including minor nodes have low expected values). 
Because we demarcated multiple MED nodes (see below), we aimed to investigate if these different Ensifer strains might have dissimilar genomic and plasmid composition as well, potentially indicative of differential nodulating and diazotrophic capabilities. Thus, we further explored the genomic composition of Ensifer throughout the plant using shotgun metagenomic sequencing for a subset of libraries used in 16S sequencing (Table S7). Libraries were prepared using the Tecan UltraLow DNA Library construction kit and sequenced on NovaSeq 6000150 PE, using NovaSeq SP reagent kit (all library construction and sequencing was performed by the Roy J. Carver Biotechnology center at the University of Illinois). We generated, demultiplexed, and adapter-trimmed fastq files using bcl2fastq v2.2 then assessed sequence quality using FastQC and performed quality control using bbduk (qtrim=rl trimq=12 hdist=1 k=27 minlenfraction $=0.6$ minlen $=40$ maxns $=1$ maq=8) [126]. To remove sequences corresponding to plant DNA, reads were mapped against the Medicago Mt 4.0 genome [127] using bowtie2 -sensitive [128]. Read pairs in which either read mapped to the Medicago reference were removed.

We used the shotgun data in two ways to examine the similarity between Ensifer found outside versus inside the nodule compartment. First, we compared whole-genome similarity of populations of Ensifer from different plant compartments of the same plant. We assembled microbial reads using metaSPAdes 3.14.0 [129]. We used sendsketch.sh in the BBtools suite [126] to identify scaffold taxonomic identity, and we compared scaffolds greater than $1 \mathrm{~kb}$ in each assembly to RefSeq [130]. Scaffolds that had best hits to any Ensifergenome were then selected, and BLASTn [131] (ungapped) was used to determine global sequence identity between Ensiferscaffolds across endophyte and nodule compartments from within the same plant (when scaffolds $\geq 100 \mathrm{~km}$ and average nucleotide identity $\geq 95 \%$ or Ensifer in RefSeq). Foliar samples were overwhelmed with Medicago sequences, and $<1 \%$ of the remaining reads mapped to $E$. medicae WSM419, so these were omitted from further analyses.

Differences in gene content could exist between otherwise similar genomes [132]. Thus we next asked whether all Ensifer had similar genome content (chromosome, pSymA, and pSymB) by comparing the relative abundance of reads mapping to each of the two symbiotic plasmids relative to those mapping to the chromosome. To do this, we first mapped reads to a reference assembly (E. medicae WSM419 assembly [133] using Bowtie 2 in $\otimes$ sensitive mode), which was the most similar and used FeatureCounts [134] to parse the output of Bowtie2 and determine the number of reads mapped onto each coding sequence. Samples with fewer than 20 reads mapping to common core gene $r p o B$ [135] belonging to Ensifer medicae WSM419 were not included in further analyses, as the signal to noise ratio of these samples was expected to be low. To ask whether symbiotic plasmid abundance might change across compartments, we calculated an estimate of the fraction of Ensifer cells possessing each of pSymA and pSymB. For each of the remaining samples, we divided the reads (per megabase) that mapped to the plasmid by the reads (per megabase) that mapped to the chromosome (representing all Ensifer cells), then tested whether this ratio differed between root endosphere and nodule compartments using a Wilcoxon-Mann-Whitney test.

\section{Declarations}


Ethics approval and consent to participate: Not applicable.

Consent for publication: Not applicable.

Availability of data and material: Datasets from 16S rRNA gene and shotgun metagenomic sequencing are archived at the Sequence Read Archives (SRA) at NCBI under the accession numbers: BioProjects (PJNAXXXXXXX) and BioSamples (SAMNXXXXXXXX-SAMNXXXXXXX).

Competing interests: The authors declare that they have no competing interests.

Funding: We acknowledge funding from the University of Illinois School of Molecular and Cellular Biology Summer Research Opportunity Program, the University of Illinois School of Integrative Biology and Department of Plant Biology, and NSF IOS-1401864 and DEB-1241212.

Authors' contributions: All authors designed the experiments. JCP, SPB, and MAG performed the experiments, SAB and JCP performed bioinformatic and statistical analyses, all authors contributed significantly to the writing, and all authors read and approved the final manuscript.

Acknowledgements: Thanks to the Sadowsky lab at the University of Minnesota for providing Ensifer strains for the inoculation experiment.

\section{References}

1. Bulgarelli D, Schlaeppi K, Spaepen S, van Themaat EVL, Schulze-Lefert P. Structure and Functions of the Bacterial Microbiota of Plants. Annu Rev Plant Biol. 2013;64:807-38.

2. Innerebner G, Knief C, Vorholt JA. Protection of Arabidopsis thaliana against Leaf-Pathogenic Pseudomonas syringae by Sphingomonas Strains in a Controlled Model System \. Appl Environ Microbiol. 2011;77:3202-10.

3. Haney $\mathrm{CH}$, Samuel BS, Bush J, Ausubel FM. Associations with rhizosphere bacteria can confer an adaptive advantage to plants. Nature Plants. 2015;1:1-9.

4. Ritpitakphong U, Falquet L, Vimoltust A, Berger A, Métraux J-P, L'Haridon F. The microbiome of the leaf surface of Arabidopsis protects against a fungal pathogen. New Phytol. 2016;210:1033-43.

5. Santhanam R, Luu VT, Weinhold A, Goldberg J, Oh Y, Baldwin IT. Native root-associated bacteria rescue a plant from a sudden-wilt disease that emerged during continuous cropping. Proc Natl Acad Sci USA. 2015;112:E5013-20.

6. Rodríguez H, Fraga R. Phosphate solubilizing bacteria and their role in plant growth promotion. Biotechnol Adv. 1999;17:319-39.

7. Richardson AE, Simpson RJ. Soil Microorganisms Mediating Phosphorus Availability Update on Microbial Phosphorus. Plant Physiol. 2011;156:989-96.

8. Ali B, Sabri AN, Ljung K, Hasnain S. Auxin production by plant associated bacteria: impact on endogenous IAA content and growth of Triticum aestivum L. Lett Appl Microbiol. 2009;48:542-7. 
9. Friesen ML, Porter SS, Stark SC, von Wettberg EJ, Sachs JL, Martinez-Romero E. Microbially Mediated Plant Functional Traits. Annual Review of Ecology, Evolution, and Systematics. 2011;42:23-46.

10. Lau JA, Lennon JT. Rapid responses of soil microorganisms improve plant fitness in novel environments. Proc Natl Acad Sci USA. 2012;109:14058-62.

11. Zhang H, Kim M-S, Sun Y, Dowd SE, Shi H, Paré PW. Soil bacteria confer plant salt tolerance by tissue-specific regulation of the sodium transporter HKT1. Mol Plant Microbe Interact. 2008;21:73744.

12. Panke-Buisse K, Poole AC, Goodrich JK, Ley RE, Kao-Kniffin J. Selection on soil microbiomes reveals reproducible impacts on plant function. ISME J. 2015;9:980-9.

13. Wagner MR, Lundberg DS, Coleman-Derr D, Tringe SG, Dangl JL, Mitchell-Olds T. Natural soil microbes alter flowering phenology and the intensity of selection on flowering time in a wild Arabidopsis relative. Ecol Lett. 2014;17:717-26.

14. Berendsen RL, Pieterse CMJ, Bakker PAHM. The rhizosphere microbiome and plant health. Trends Plant Sci. 2012;17:478-86.

15. Gehring CA, Sthultz CM, Flores-Rentería L, Whipple AV, Whitham TG. Tree genetics defines fungal partner communities that may confer drought tolerance. Proc Natl Acad Sci USA. 2017;114:1116974.

16. Beilsmith K, Thoen MPM, Brachi B, Gloss AD, Khan MH, Bergelson J. Genome-wide association studies on the phyllosphere microbiome: Embracing complexity in host-microbe interactions. Plant J. 2019;97:164-81.

17. Timmis K, de Vos WM, Ramos JL, Vlaeminck SE, Prieto A, Danchin A, et al. The contribution of microbial biotechnology to sustainable development goals. Microb Biotechnol. 2017;10:984-7.

18. Busby PE, Soman C, Wagner MR, Friesen ML, Kremer J, Bennett A, et al. Research priorities for harnessing plant microbiomes in sustainable agriculture. PLoS Biol. 2017;15:e2001793.

19. Zahn G, Amend AS. Foliar microbiome transplants confer disease resistance in a criticallyendangered plant. PeerJ [Internet]. 2017 [cited 2020 Mar 10];5. Available from: .

20. Handelsman J. Metagenomics: application of genomics to uncultured microorganisms. Microbiol Mol Biol Rev. 2004;68:669-85.

21. Bordenstein SR, Theis KR. Host Biology in Light of the Microbiome: Ten Principles of Holobionts and Hologenomes. PLOS Biology Public Library of Science. 2015;13:e1002226.

22. Rosenberg E, Zilber-Rosenberg I. Microbes Drive Evolution of Animals and Plants: the Hologenome Concept. mBio [Internet]. 2016 [cited 2020 Mar 11];7. Available from: .

23. Bouffaud M-L, Poirier M-A, Muller D, Moënne-Loccoz Y. Root microbiome relates to plant host evolution in maize and other Poaceae. Environ Microbiol. 2014;16:2804-14.

24. Redford AJ, Bowers RM, Knight R, Linhart Y, Fierer N. The ecology of the phyllosphere: geographic and phylogenetic variability in the distribution of bacteria on tree leaves. Environ Microbiol. 
2010;12:2885-93.

25. Schlaeppi K, Dombrowski N, Oter RG, Ver Loren van Themaat E, Schulze-Lefert P. Quantitative divergence of the bacterial root microbiota in Arabidopsis thaliana relatives. Proc Natl Acad Sci USA. 2014;111:585-92.

26. Weinert N, Piceno Y, Ding G-C, Meincke R, Heuer H, Berg G, et al. PhyloChip hybridization uncovered an enormous bacterial diversity in the rhizosphere of different potato cultivars: many common and few cultivar-dependent taxa. FEMS Microbiol Ecol. 2011;75:497-506.

27. Zancarini A, Mougel C, Voisin A-S, Prudent M, Salon C, Munier-Jolain N. Soil Nitrogen Availability and Plant Genotype Modify the Nutrition Strategies of M. truncatula and the Associated Rhizosphere Microbial Communities. PLoS One [Internet]. 2012 [cited 2020 Mar 10];7. Available from: .

28. Horton MW, Bodenhausen N, Beilsmith K, Meng D, Muegge BD, Subramanian S, et al. Genome-wide association study of Arabidopsis thaliana leaf microbial community. Nat Commun. 2014;5:5320.

29. Wagner MR, Lundberg DS, Del Rio TG, Tringe SG, Dangl JL, Mitchell-Olds T. Host genotype and age shape the leaf and root microbiomes of a wild perennial plant. Nat Commun. 2016;7:12151.

30. Walters WA, Jin Z, Youngblut N, Wallace JG, Sutter J, Zhang W, et al. Large-scale replicated field study of maize rhizosphere identifies heritable microbes. Proc Natl Acad Sci USA. 2018;115:736873.

31. Peiffer JA, Spor A, Koren O, Jin Z, Tringe SG, Dangl JL, et al. Diversity and heritability of the maize rhizosphere microbiome under field conditions. Proc Natl Acad Sci USA. 2013;110:6548-53.

32. Shakya M, Gottel N, Castro H, Yang ZK, Gunter L, Labbé J, et al. A multifactor analysis of fungal and bacterial community structure in the root microbiome of mature Populus deltoides trees. PLoS ONE. 2013;8:e76382.

33. Edwards J, Johnson C, Santos-Medellín C, Lurie E, Podishetty NK, Bhatnagar S, et al. Structure, variation, and assembly of the root-associated microbiomes of rice. Proc Natl Acad Sci USA. 2015;112:E911-20.

34. Shade A, Jones SE, Caporaso JG, Handelsman J, Knight R, Fierer N, et al. Conditionally rare taxa disproportionately contribute to temporal changes in microbial diversity. mBio. 2014;5:e0137101314.

35. Goss-Souza D, Mendes LW, Borges CD, Baretta D, Tsai SM, Rodrigues JLM. Soil microbial community dynamics and assembly under long-term land use change. FEMS Microbiol Ecol. 2017;93.

36. Rastogi G, Coaker GL, Leveau JHJ. New insights into the structure and function of phyllosphere microbiota through high-throughput molecular approaches. FEMS Microbiol Lett. 2013;348:1-10.

37. Vorholt JA. Microbial life in the phyllosphere. Nat Rev Microbiol. 2012;10:828-40.

38. Hacquard S, Spaepen S, Garrido-Oter R, Schulze-Lefert P. Interplay Between Innate Immunity and the Plant Microbiota. Annu Rev Phytopathol. 2017;55:565-89.

39. Hersch-Green El, Turley NE, Johnson MTJ. Community genetics: what have we accomplished and where should we be going? Philos Trans R Soc Lond B Biol Sci. 2011;366:1453-60. 
40. Tiffin P, Moeller DA. Molecular evolution of plant immune system genes. Trends Genet. 2006;22:66270.

41. Pérez-Jaramillo JE, Mendes R, Raaijmakers JM. Impact of plant domestication on rhizosphere microbiome assembly and functions. Plant Mol Biol. 2016;90:635-44.

42. Bouffaud M-L, Kyselková M, Gouesnard B, Grundmann G, Muller D, Moënne-Loccoz Y. Is diversification history of maize influencing selection of soil bacteria by roots? Mol Ecol. 2012;21:195-206.

43. Bulgarelli D, Garrido-Oter R, Münch PC, Weiman A, Dröge J, Pan Y, et al. Structure and function of the bacterial root microbiota in wild and domesticated barley. Cell Host Microbe. 2015;17:392-403.

44. Graham PH, Vance CP. Legumes: importance and constraints to greater use. Plant Physiol. 2003;131:872-7.

45. Oldroyd GED. Speak, friend, and enter: signalling systems that promote beneficial symbiotic associations in plants. Nat Rev Microbiol. 2013;11:252-63.

46. Wang D, Yang S, Tang F, Zhu H. Symbiosis specificity in the legume: rhizobial mutualism. Cell Microbiol. 2012;14:334-42.

47. Genre A, Russo G. Does a Common Pathway Transduce Symbiotic Signals in Plant-Microbe Interactions? Front Plant Sci [Internet]. 2016 [cited 2020 Mar 10];7. Available from: .

48. Rey T, Chatterjee A, Buttay M, Toulotte J, Schornack S. Medicago truncatula symbiosis mutants affected in the interaction with a biotrophic root pathogen. New Phytol. 2015;206:497-500.

49. Rey T, Nars A, Bonhomme M, Bottin A, Huguet S, Balzergue S, et al. NFP, a LysM protein controlling Nod factor perception, also intervenes in Medicago truncatula resistance to pathogens. New Phytol. 2013;198:875-86.

50. Lace B, Ott T. Commonalities and Differences in Controlling Multipartite Intracellular Infections of Legume Roots by Symbiotic Microbes. Plant Cell Physiol. 2018;59:661-72.

51. Zgadzaj R, Garrido-Oter R, Jensen DB, Koprivova A, Schulze-Lefert P, Radutoiu S. Root nodule symbiosis in Lotus japonicus drives the establishment of distinctive rhizosphere, root, and nodule bacterial communities. Proc Natl Acad Sci USA. 2016;113:E7996-8005.

52. Tjepkema JD, Yocum CS. Measurement of oxygen partial pressure within soybean nodules by oxygen microelectrodes. Planta. 1974;119:351-60.

53. $10.3389 /$ fpls.2015.01133/full

Avenhaus U, Cabeza RA, Liese R, Lingner A, Dittert K, Salinas-Riester G, et al. Short-Term Molecular Acclimation Processes of Legume Nodules to Increased External Oxygen Concentration. Front Plant Sci [Internet]. 2016 [cited 2020 Mar 11];6. Available from: .

54. Libault M. The Carbon-Nitrogen Balance of the Nodule and Its Regulation under Elevated Carbon Dioxide Concentration. Biomed Res Int [Internet]. 2014 [cited 2020 Mar 10];2014. Available from: .

55. Scheublin TR, Ridgway KP, Young JPW, van der Heijden MGA. Nonlegumes, legumes, and root nodules harbor different arbuscular mycorrhizal fungal communities. Appl Environ Microbiol. 
2004;70:6240-6.

56. Martínez-Hidalgo P, Hirsch AM. The Nodule Microbiome: N2-Fixing Rhizobia Do Not Live Alone. Phytobiomes Journal. 2017;1:70-82.

57. Santos MS, Nogueira MA, Hungria M. Microbial inoculants: reviewing the past, discussing the present and previewing an outstanding future for the use of beneficial bacteria in agriculture. AMB Express. 2019;9:205.

58. Lesins KA, Lesins I. Genus Medicago (Leguminosae): A Taxogenetic Study [Internet]. Springer Netherlands; 1979 [cited 2020 Mar 25]. Available from: .

59. Barker DG, Bianchi S, Blondon F, Dattée Y, Duc G, Essad S, et al. Medicago truncatula, a model plant for studying the molecular genetics of theRhizobium-legume symbiosis. Plant Mol Biol Rep. 1990;8:40-9.

60. Cook DR. Medicago truncatula-a model in the making! Curr Opin Plant Biol. 1999;2:301-4.

61. Young ND, Debellé F, Oldroyd GED, Geurts R, Cannon SB, Udvardi MK, et al. The Medicago genome provides insight into the evolution of rhizobial symbioses. Nature. 2011;480:520-4.

62. 10.3389/fmicb.2019.00481/full

Bonito G, Benucci GMN, Hameed K, Weighill D, Jones P, Chen K-H, et al. Fungal-Bacterial Networks in the Populus Rhizobiome Are Impacted by Soil Properties and Host Genotype. Front Microbiol [Internet]. Frontiers; 2019 [cited 2020 Mar 25];10. Available from: .

63. Liu F, Hewezi T, Lebeis SL, Pantalone V, Grewal PS, Staton ME. Soil indigenous microbiome and plant genotypes cooperatively modify soybean rhizosphere microbiome assembly. BMC Microbiol. 2019;19:201.

64. Veach AM, Morris R, Yip DZ, Yang ZK, Engle NL, Cregger MA, et al. Rhizosphere microbiomes diverge among Populus trichocarpa plant-host genotypes and chemotypes, but it depends on soil origin. Microbiome. 2019;7:76.

65. Bruijn FJ de. The Model Legume Medicago truncatula, 2 Volume Set. John Wiley \& Sons; 2020.

66. Fierer N, Strickland MS, Liptzin D, Bradford MA, Cleveland CC. Global patterns in belowground communities. Ecol Lett. 2009;12:1238-49.

67. Yeoh YK, Dennis PG, Paungfoo-Lonhienne C, Weber L, Brackin R, Ragan MA, et al. Evolutionary conservation of a core root microbiome across plant phyla along a tropical soil chronosequence. Nat Commun Nature Publishing Group. 2017;8:1-9.

68. Burns JH, Anacker BL, Strauss SY, Burke DJ. Soil microbial community variation correlates most strongly with plant species identity, followed by soil chemistry, spatial location and plant genus. AoB Plants. 2015;7.

69. Mendes R, Garbeva P, Raaijmakers JM. The rhizosphere microbiome: significance of plant beneficial, plant pathogenic, and human pathogenic microorganisms. FEMS Microbiol Rev. 2013;37:634-63.

70. Rolfe SA, Griffiths J, Ton J. Crying out for help with root exudates: adaptive mechanisms by which stressed plants assemble health-promoting soil microbiomes. Curr Opin Microbiol. 2019;49:73-82. 
71. Lareen $A$, Burton F, Schäfer P. Plant root-microbe communication in shaping root microbiomes. Plant Mol Biol. 2016;90:575-87.

72. Bonnin I, Huguet T, Gherardi M, Prosperi JM, Olivieri I. High Level of Polymorphism and Spatial Structure in a Selfing Plant Species, Medicago truncatula (Leguminosae), Shown Using RAPD Markers. American Journal of Botany Botanical Society of America. 1996;83:843-55.

73. Lundberg DS, Lebeis SL, Paredes SH, Yourstone S, Gehring J, Malfatti S, et al. Defining the core Arabidopsis thaliana root microbiome. Nature Nature Publishing Group. 2012;488:86-90.

74. Bulgarelli D, Rott M, Schlaeppi K, Themaat EVL van, Ahmadinejad N, Assenza F, et al. Revealing structure and assembly cues for Arabidopsis root-inhabiting bacterial microbiota. Nature Nature Publishing Group. 2012;488:91-5.

75. Ehinger M, Mohr TJ, Starcevich JB, Sachs JL, Porter SS, Simms EL. Specialization-generalization trade-off in a Bradyrhizobium symbiosis with wild legume hosts. BMC Ecol. 2014;14:8.

76. Batstone RT, Carscadden KA, Afkhami ME, Frederickson ME. Using niche breadth theory to explain generalization in mutualisms. Ecology. 2018;99:1039-50.

77. Simonsen AK, Dinnage R, Barrett LG, Prober SM, Thrall PH. Symbiosis limits establishment of legumes outside their native range at a global scale. Nat Commun Nature Publishing Group. 2017;8:1-9.

78. Harrison TL, Wood CW, Heath KD, Stinchcombe JR. Geographically structured genetic variation in the Medicago lupulina-Ensifer mutualism. Evolution. 2017;71:1787-801.

79. Fitzpatrick CR, Copeland J, Wang PW, Guttman DS, Kotanen PM, Johnson MTJ. Assembly and ecological function of the root microbiome across angiosperm plant species. PNAS National Academy of Sciences. 2018;115:E1157-65.

80. Tkacz A, Bestion E, Bo Z, Hortala M, Poole PS. Influence of Plant Fraction, Soil, and Plant Species on Microbiota: a Multikingdom Comparison. mBio [Internet]. American Society for Microbiology; 2020 [cited 2020 Mar 25];11. Available from: .

81. Agler MT, Ruhe J, Kroll S, Morhenn C, Kim S-T, Weigel D, et al. Microbial Hub Taxa Link Host and Abiotic Factors to Plant Microbiome Variation. PLoS Biol. 2016;14:e1002352.

82. Lebeis SL, Paredes SH, Lundberg DS, Breakfield N, Gehring J, McDonald M, et al. PLANT MICROBIOME. Salicylic acid modulates colonization of the root microbiome by specific bacterial taxa. Science. 2015;349:860-4.

83. Bergelson J, Mittelstrass J, Horton MW. Characterizing both bacteria and fungi improves understanding of the Arabidopsis root microbiome. Sci Rep [Internet]. 2019 [cited 2020 Mar 25];9. Available from: .

84. Wagner MR, Busby PE, Balint-Kurti P. Analysis of leaf microbiome composition of near-isogenic maize lines differing in broad-spectrum disease resistance. New Phytol. 2020;225:2152-65.

85. Parker MA. Local Population Differentiation for Compatibility in an Annual Legume and Its HostSpecific Fungal Pathogen. Evolution. 1985;39:713-23. 
86. Burdon JJ, Gibson AH, Searle SD, Woods MJ, Brockwell J. Variation in the Effectiveness of Symbiotic Associations between Native Rhizobia and Temperate Australian Acacia: Within-Species Interactions. Journal of Applied Ecology. [British Ecological Society, Wiley]; 1999;36:398-408.

87. Heath KD. Intergenomic epistasis and coevolutionary constraint in plants and rhizobia. Evolution. 2010;64:1446-58.

88. Burghardt LT, Epstein B, Guhlin J, Nelson MS, Taylor MR, Young ND, et al. Select and resequence reveals relative fitness of bacteria in symbiotic and free-living environments. PNAS National Academy of Sciences. 2018;115:2425-30.

89. Dangl JL, Horvath DM, Staskawicz BJ. Pivoting the plant immune system from dissection to deployment. Science. 2013;341:746-51.

90. Morella NM, Weng FC-H, Joubert PM, Metcalf CJE, Lindow SE, Koskella B. Successive passaging of a plant-associated microbiome reveals robust habitat and host genotype-dependent selection. 2019.

91. Bendall ML, Stevens SL, Chan L-K, Malfatti S, Schwientek P, Tremblay J, et al. Genome-wide selective sweeps and gene-specific sweeps in natural bacterial populations. ISME J Nature Publishing Group. 2016;10:1589-601.

92. Garud NR, Good BH, Hallatschek O, Pollard KS. Evolutionary dynamics of bacteria in the gut microbiome within and across hosts. PLOS Biology Public Library of Science. 2019;17:e3000102.

93. Knief C, Delmotte N, Chaffron S, Stark M, Innerebner G, Wassmann R, et al. Metaproteogenomic analysis of microbial communities in the phyllosphere and rhizosphere of rice. ISME J. 2012;6:1378-90.

94. Ottesen AR, González Peña A, White JR, Pettengill JB, Li C, Allard S, et al. Baseline survey of the anatomical microbial ecology of an important food plant: Solanum lycopersicum (tomato). BMC Microbiol. 2013;13:114.

95. Garrido-Oter R, Nakano RT, Dombrowski N, Ma K-W, AgBiome Team, McHardy AC, et al. Modular Traits of the Rhizobiales Root Microbiota and Their Evolutionary Relationship with Symbiotic Rhizobia. Cell Host Microbe. 2018;24:155-67.e5.

96. Garcia-Fraile P, Seaman JC, Karunakaran R, Edwards A, Poole PS, Downie JA. Arabinose and protocatechuate catabolism genes are important for growth of Rhizobium leguminosarum biovar viciae in the pea rhizosphere. Plant Soil. 2015;390:251-64.

97. Galibert F, Finan TM, Long SR, Puhler A, Abola P, Ampe F, et al. The composite genome of the legume symbiont Sinorhizobium meliloti. Science. 2001;293:668-72.

98. diCenzo GC, Checcucci A, Bazzicalupo M, Mengoni A, Viti C, Dziewit L, et al. Metabolic modelling reveals the specialization of secondary replicons for niche adaptation in Sinorhizobium meliloti. Nat Commun. 2016;7:12219.

99. Béna G, Lyet A, Huguet T, Olivieri I. Medicago-Sinorhizobium symbiotic specificity evolution and the geographic expansion of Medicago. J Evol Biol. 2005;18:1547-58.

100. Martínez-Romero E. Coevolution in Rhizobium-Legume Symbiosis? DNA and Cell Biology. Mary Ann Liebert, Inc., publishers; 2009;28:361-70. 
101. Oldroyd GED, Murray JD, Poole PS, Downie JA. The rules of engagement in the legume-rhizobial symbiosis. Annu Rev Genet. 2011;45:119-44.

102. Weese DJ, Heath KD, Dentinger BTM, Lau JA. Long-term nitrogen addition causes the evolution of less-cooperative mutualists. Evolution. 2015;69:631-42.

103. Sachs JL, Russell JE, Lii YE, Black KC, Lopez G, Patil AS. Host control over infection and proliferation of a cheater symbiont. J Evol Biol. 2010;23:1919-27.

104. Batstone RT, Dutton EM, Wang D, Yang M, Frederickson ME. The evolution of symbiont preference traits in the model legume Medicago truncatula. New Phytol. 2017;213:1850-61.

105. Thilakarathna MS, Raizada MN. A meta-analysis of the effectiveness of diverse rhizobia inoculants on soybean traits under field conditions. Soil Biol Biochem. 2017;105:177-96.

106. Heath KD, Stinchcombe JR. Explaining mutualism variation: a new evolutionary paradox? Evolution. 2014;68:309-17.

107. Grillo MA, De Mita S, Burke PV, Solórzano-Lowell KLS, Heath KD. Intrapopulation genomics in a model mutualist: Population structure and candidate symbiosis genes under selection in Medicago truncatula. Evolution. 2016;70:2704-17.

108. De Mita S, Santoni S, Ronfort J, Bataillon T. Adaptive evolution of the symbiotic gene NORK is not correlated with shifts of rhizobial specificity in the genus Medicago. BMC Evol Biol. 2007;7:210.

109. Trung BC, Yoshida S. Improvement of Leonard jar assembly for screening of effective rhizobium. Soil Science Plant Nutrition. 1983;29:97-100.

110. Brown SP, Leopold DR, Busby PE. Protocols for Investigating the Leaf Mycobiome Using HighThroughput DNA Sequencing. Methods Mol Biol. 2018;1848:39-51.

111. Lawley RA, Campbell R, Newman El. Composition of the bacterial flora of the rhizosphere of three grassland plants grown separately and in mixtures. Soil Biol Biochem. 1983;15:605-7.

112. Jones JM, Heath KD, Ferrer A, Brown SP, Canam T, Dalling JW. Wood decomposition in aquatic and terrestrial ecosystems in the tropics: contrasting biotic and abiotic processes. FEMS Microbiol Ecol [Internet]. Oxford Academic; 2019 [cited 2020 Mar 29];95. Available from: .

113. Schloss PD, Westcott SL, Ryabin T, Hall JR, Hartmann M, Hollister EB, et al. Introducing mothur: Open-Source, Platform-Independent, Community-Supported Software for Describing and Comparing Microbial Communities. Appl Environ Microbiol American Society for Microbiology. 2009;75:753741.

114. Brown SP, Veach AM, Rigdon-Huss AR, Grond K, Lickteig SK, Lothamer K, et al. Scraping the bottom of the barrel: are rare high throughput sequences artifacts? Fungal Ecology. 2015;13:221-5.

115. Oliver AK, Brown SP, Callaham MA, Jumpponen A. Polymerase matters: non-proofreading enzymes inflate fungal community richness estimates by up to 15\%. Fungal Ecology. 2015;15:86-9.

116. Anderson MJ. A new method for non-parametric multivariate analysis of variance. Austral Ecol. 2001;26:32-46. 
117. Oksanen J, Blanchet FG, Friendly M, Kindt R, Legendre P, McGlinn D, et al. vegan: Community Ecology Package [Internet]. 2019 [cited 2020 Mar 25]. Available from: .

118. Boedigheimer MJ, Wolfinger RD, Bass MB, Bushel PR, Chou JW, Cooper M, et al. Sources of variation in baseline gene expression levels from toxicogenomics study control animals across multiple laboratories. BMC Genom. 2008;9:285.

119. Heath KD, Burke PV, Stinchcombe JR. Coevolutionary genetic variation in the legume-rhizobium transcriptome. Mol Ecol. 2012;21:4735-47.

120. Brown S, Veach A, Horton J, Ford E, Jumpponen A, Baird R. Context dependent fungal and bacterial soil community shifts in response to recent wildfires in the Southern Appalachian Mountains. Forest Ecology and Management. 2019;451.

121. Segata N, Izard J, Waldron L, Gevers D, Miropolsky L, Garrett WS, et al. Metagenomic biomarker discovery and explanation. Genome Biol. 2011;12:R60.

122. Raup DM, Crick RE. Measurement of Faunal Similarity in Paleontology. Journal of Paleontology Paleontological Society. 1979;53:1213-27.

123. Chase JM, Kraft NJB, Smith KG, Vellend M, Inouye BD. Using null models to disentangle variation in community dissimilarity from variation in a-diversity. Ecosphere. 2011;2:art24.

124. Hammer O, Harper DAT, Ryan PD. PAST: Paleontological Statistics Software Package for Education and Data Analysis. 2001;9.

125. Eren AM, Morrison HG, Lescault PJ, Reveillaud J, Vineis JH, Sogin ML. Minimum entropy decomposition: unsupervised oligotyping for sensitive partitioning of high-throughput marker gene sequences. ISME J. 2015;9:968-79.

126. Bushnell B, Rood J, Singer E. BBMerge - Accurate paired shotgun read merging via overlap. PLoS ONE. 2017;12:e0185056.

127. Tang H, Krishnakumar V, Bidwell S, Rosen B, Chan A, Zhou S, et al. An improved genome release (version Mt4.0) for the model legume Medicago truncatula. BMC Genom. 2014;15:312.

128. Langmead B, Salzberg SL. Fast gapped-read alignment with Bowtie 2. Nat Methods. 2012;9:357-9.

129. Nurk S, Meleshko D, Korobeynikov A, Pevzner PA. metaSPAdes: a new versatile metagenomic assembler. Genome Res. 27. Cold Spring Harbor: Cold Spring Harbor Lab Press, Publications Dept;" 2017. pp. 824-34.

130. O'Leary NA, Wright MW, Brister JR, Ciufo S, Haddad D, McVeigh R, et al. Reference sequence (RefSeq) database at NCBI: current status, taxonomic expansion, and functional annotation. Nucleic Acids Res. 2016;44:D733-45.

131. Camacho C, Coulouris G, Avagyan V, Ma N, Papadopoulos J, Bealer K, et al. BLAST+: architecture and applications. BMC Bioinformatics. 2009;10:421.

132. Coleman ML, Chisholm SW. Ecosystem-specific selection pressures revealed through comparative population genomics. Proc Natl Acad Sci USA. 2010;107:18634-9. 
133. Reeve W, Chain P, O’Hara G, Ardley J, Nandesena K, Bräu L, et al. Complete genome sequence of the Medicago microsymbiont Ensifer (Sinorhizobium) medicae strain WSM419. Stand Genomic Sci. 2010;2:77-86.

\section{Liao Y, Smyth GK, Shi W. featureCounts: an efficient general purpose program for assigning} sequence reads to genomic features. Bioinformatics. 2014;30:923-30.

\section{Adékambi T, Drancourt M, Raoult D. The rpoB gene as a tool for clinical microbiologists. Trends} Microbiol. 2009;17:37-45.

\section{Tables}

Table 1: Results from modified Principal Variance Component Analysis (PVCA) enumerating the amount of community variation explained by soil origin (France of Corsica), plant genotype (G1, G27, G96), plant compartments (Rhizosphere, Root, Nodule, Leaf) and all possible interactions. Further, diversity estimator ANOVA results are presented across the same design. Complement of Simpson's Diversity and Evenness were transformed using logit transformation and Richness was transformed using Box-Cox functions prior to analysis.

\begin{tabular}{|c|c|c|c|c|}
\hline Test & Variance Explained -PVCA (\%) & Diversity (1-D) & Evenness $\left(E_{d}\right)$ & OTU Richness $\left(\mathrm{S}_{\mathrm{obs}}\right)$ \\
\hline Soil Origin & 3.207 & $\mathrm{~F}=0.685, \mathrm{P}=0.411$ & $\mathrm{~F}=0.767, \mathrm{P}=0.384$ & $\mathrm{~F}=1.845, \mathrm{P}=0.178$ \\
\hline Genotype & 1.274 & $\mathrm{~F}=0.054, \mathrm{P}=0.947$ & $\mathrm{~F}=1.356, \mathrm{P}=0.265$ & $\mathrm{~F}=0.0704, \mathrm{P}=0.498$ \\
\hline Compartment & 3.231 & $\mathrm{~F}=14.151, \mathrm{P}<0.001$ & $\mathrm{~F}=3.171, \mathrm{P}=0.029$ & $\mathrm{~F}=39.509, \mathrm{P}<0.001$ \\
\hline Soil Origin $\mathrm{x}$ Genotype & 3.222 & $\mathrm{~F}=0.297, \mathrm{P}=0.753$ & $\mathrm{~F}=1.169, \mathrm{P}=0.316$ & $\mathrm{~F}=0.215, \mathrm{P}=0.807$ \\
\hline Soil Origin $\mathrm{x}$ Compartment & 23.098 & $\mathrm{~F}=1.582, \mathrm{P}=0.202$ & $\mathrm{~F}=1.123, \mathrm{P}=0.346$ & $\mathrm{~F}=2.381, \mathrm{P}=0.077$ \\
\hline Genotype x Compartment & 6.295 & $\mathrm{~F}=0.884, \mathrm{P}=0.511$ & $\mathrm{~F}=0.702, \mathrm{P}=0.649$ & $\mathrm{~F}=1.379, \mathrm{P}=0.235$ \\
\hline Soil Origin x Genotype x Compartment & 0.369 & $\mathrm{~F}=0.634, \mathrm{P}=0.703$ & $\mathrm{~F}=0.496, \mathrm{P}=0.809$ & $\mathrm{~F}=0.488, \mathrm{P}=0.815$ \\
\hline Residual & 59.302 & & & \\
\hline
\end{tabular}

Table 2: PerMANOVAs by compartment testing for the effects of soil origin (Corsica or France) and plant genotype on bacterial community composition. PerMANOVA tests are based on a Bray-Curtis dissimilarity matrix using an iterative subsampling of a depth of 1500 sequences (1000 iterations) per sample. Pseudo-F test statistics, degrees of freedom, and P-values are presented, and significant tests are displayed in bold and in italics.

\begin{tabular}{|l|l|l|l|l|}
\hline Test & Soil Origin Pseudo- $F_{d f}$ & Soil Origin P-value & Genotype Pseudo- $F_{d f}$ & Genotype P-value \\
\hline Rhizosphere & $F_{1,28}=4.838$ & 0.001 & $F_{2,27}=0.762$ & 0.679 \\
\hline Root & $\mathrm{F}_{1,28}=1.006$ & 0.374 & $F_{2,27}=1.982$ & 0.026 \\
\hline Nodule & $\mathrm{F}_{1,27}=1.057$ & 0.330 & $\mathrm{~F}_{2,67}=0.506$ & 0.941 \\
\hline Leaf & $\mathrm{F}_{1,28}=0.501$ & 0.801 & $\mathrm{~F}_{2,27}=1.052$ & 0.411 \\
\hline
\end{tabular}




\section{Additional Files}

\section{Additional file 1}

Format: Excel workbook (.xlsx)

Title of data: Table S1

Description of data: Full matrix of sequence counts for OTUs (retained) with sample identification. Listed in sample name are soil location ( $C$ - Corsica; F - France), genotype $(1,27,96)$, replication number $(a, b$, c, d, e), and plant compartment ( $\mathrm{L}$ - Leaf; $\mathrm{N}$ - Nodule; R - Root (endosphere); and S - Soil (rhizosphere)).

\section{Additional file 2}

Format: Excel workbook (.xIsx)

Title of data: Table S2

Description of data: Full OTU information including total sequence count, sequence distribution across compartments, sequence distribution across genotypes, sequence distribution across soil location, LEfSe results (where significant) and to which compartment, LEfSe results (where significant) and to which soils, representative OTU sequences, and full OTU taxonomy string (with bootstrap support for taxonomic rank).

\section{Additional file 3}

Format: PDF file

Title of data: Figure S1

Description of data: Venn diagrams of shared OTUs across compartments (a) and soil sources (b). Only OTUs greater than 10 sequences within a particular compartment are included.

\section{Additional file 4}

Format: PDF file

Title of data: Figure S2

Description of data: Nonmetric Multidimensional Scaling plot (Bray-Curtis) of rhizopsheric bacteria plotted by soil origin (France or Corsica). PERMANOVA statistics indicate that communities differ 
between soil origin. Insert represents Axis 3 loading scores (explains $6.61 \%$ of community variation) across soil origin (t-test) showing Corsican samples have lower average loading scores than French soils.

\section{Additional file 5}

Format: Excel workbook (.xIsx)

Title of data: Table S3

Description of data: Core OTUs with taxonomy found within nodule communities across sampling design, an OTU was defined as core if present in $>50 \%$ nodule samples

\section{Additional file 6}

Format: Word document (.docx)

Title of data: Table S4

Description of data: ANOVA results of Ensifer Inoculation experiment are presented across compartments, Ensifer genotypes, and compartment $x$ genotype interactions. Complement of Simpson's Diversity and Evenness were transformed using logit transformation and Richness was transformed using Box-Cox functions $(\lambda=0.478)$ prior to analysis.

\section{Additional file 7}

Format: Excel workbook (.xIsx)

Title of data: Table S5

Description of data: Results of BLASTn identification of all demarcated Ensifer MED nodes. Where these MED nodes best matched Ensifer sp. or our OTU1 representative sequence, full blast results are also presented. The four nodes that matched to OTU1 were used for analysis.

\section{Additional file 8:}

Format: PDF file (.pdf)

Title of data: Supplementary Text S1

Description of data: Supplementary methods for DNA extraction, amplification, and sequencing, and bioinformatics for 16S rRNA gene sequencing.

\section{Additional file 9}

Format: Excel workbook (.xIsx) 
Title of data: Table S6

Description of data: Primer and MID sequence information for 16S rRNA gene amplicon sequencing, with sample identifications. MIDs and forward primer (515f) were used for secondary PCR reactions.

\section{Additional file 10}

Format: Excel workbook (.xIsx)

Title of data: Table S7

Description of data: Sequencing and Assembly Information for Metagenomic Samples. Count of sequences per sample before and after quality control, as well as count of sequences considered plant sequences and Ensifer sequences for each sample. Summarization of reads mapped to plasmid and chromosome for Ensifer medicae WSM419 for each sample.

\section{Figures}


a.

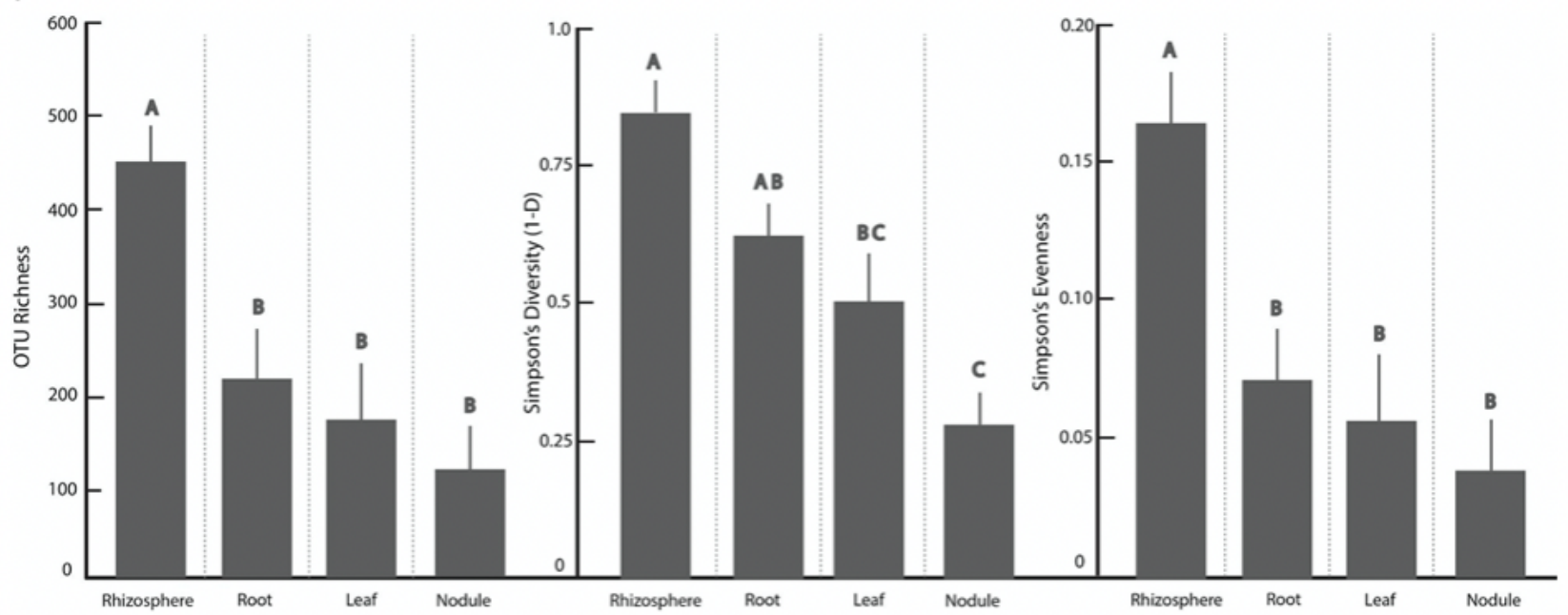

b.

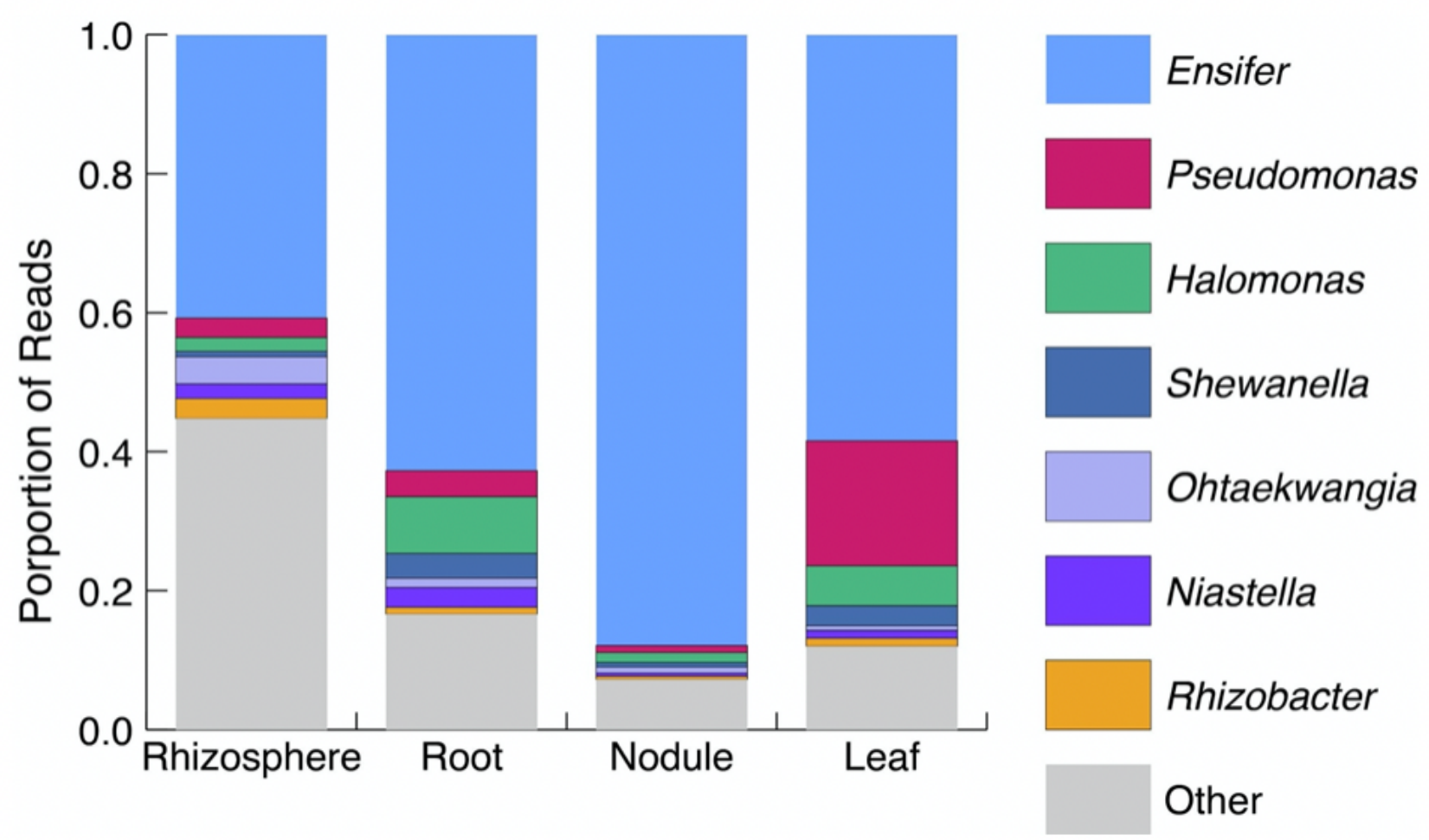

Figure 1

Bacterial diversity metrics (a) and abundance (Mean \pm SE) of the most abundant bacterial OTUs (b) for the four compartments studied. All estimates based on iterative subsampling (1500 sequences per iteration at 1000 iterations). Letters represent significant differences (Tukey HSD) across compartments. 
a.

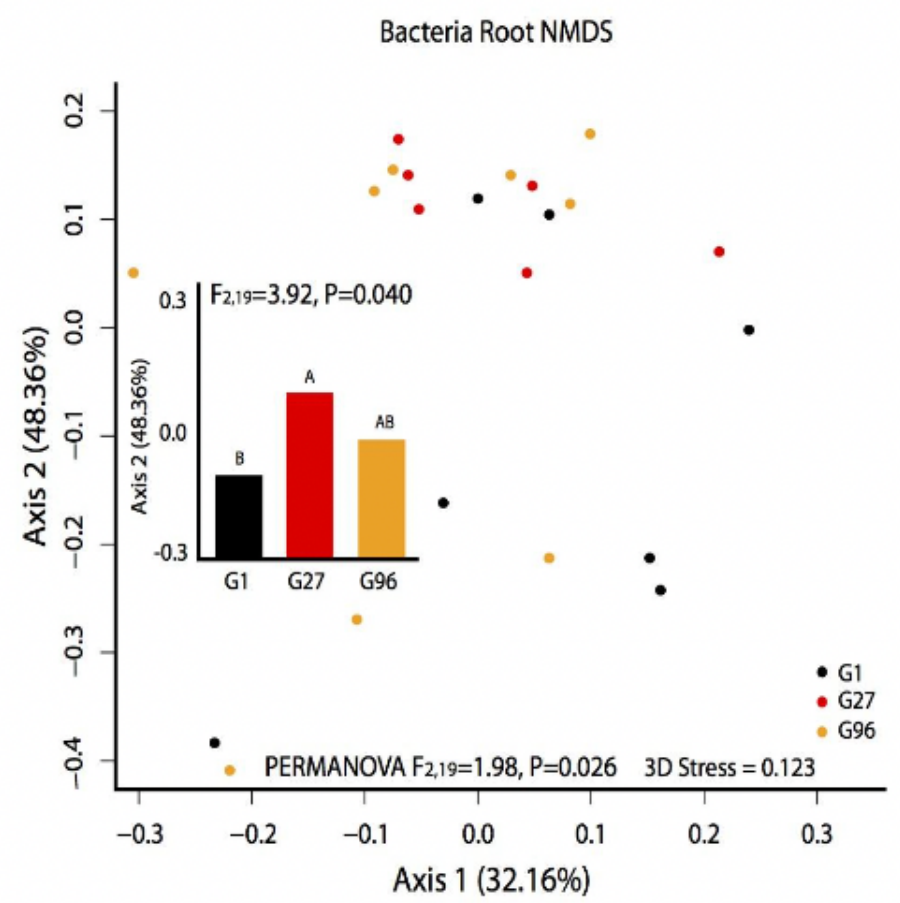

b.

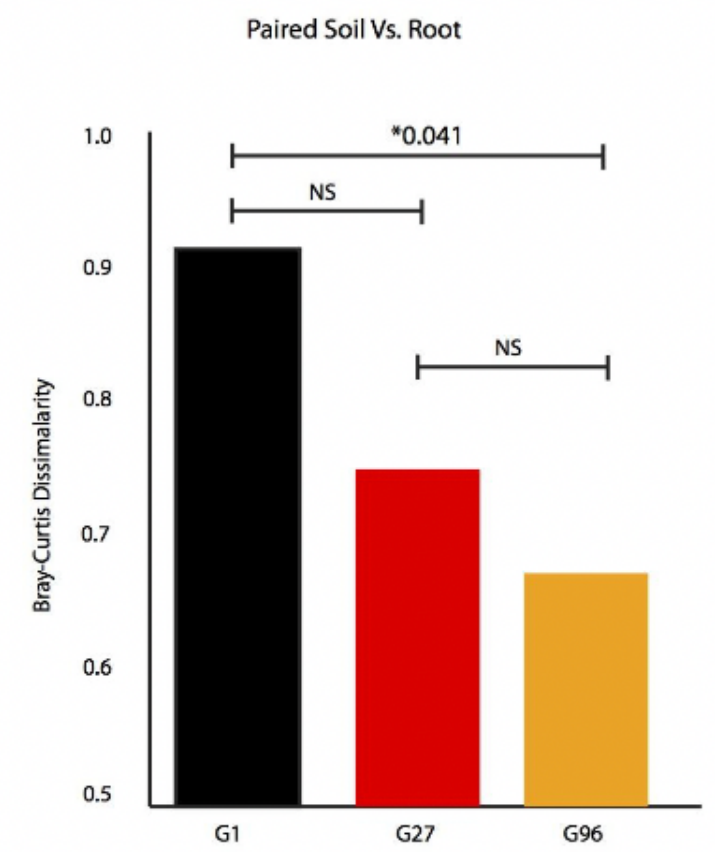

\section{Figure 2}

Bacterial communities in the root endosphere respond to plant genotype. Panel a: Nonmetric Multidimensional Scaling plot (Bray-Curtis) of bacterial root endophytes plotted by genotype, with insert showing Axis 2 loading scores (explains $48.36 \%$ of community variation) across genotypes (ANOVA). Panel b: Average bacteria Bray-Curtis dissimilarity values between paired rhizosphere and root endosphere samples (samples are paired by plant). 

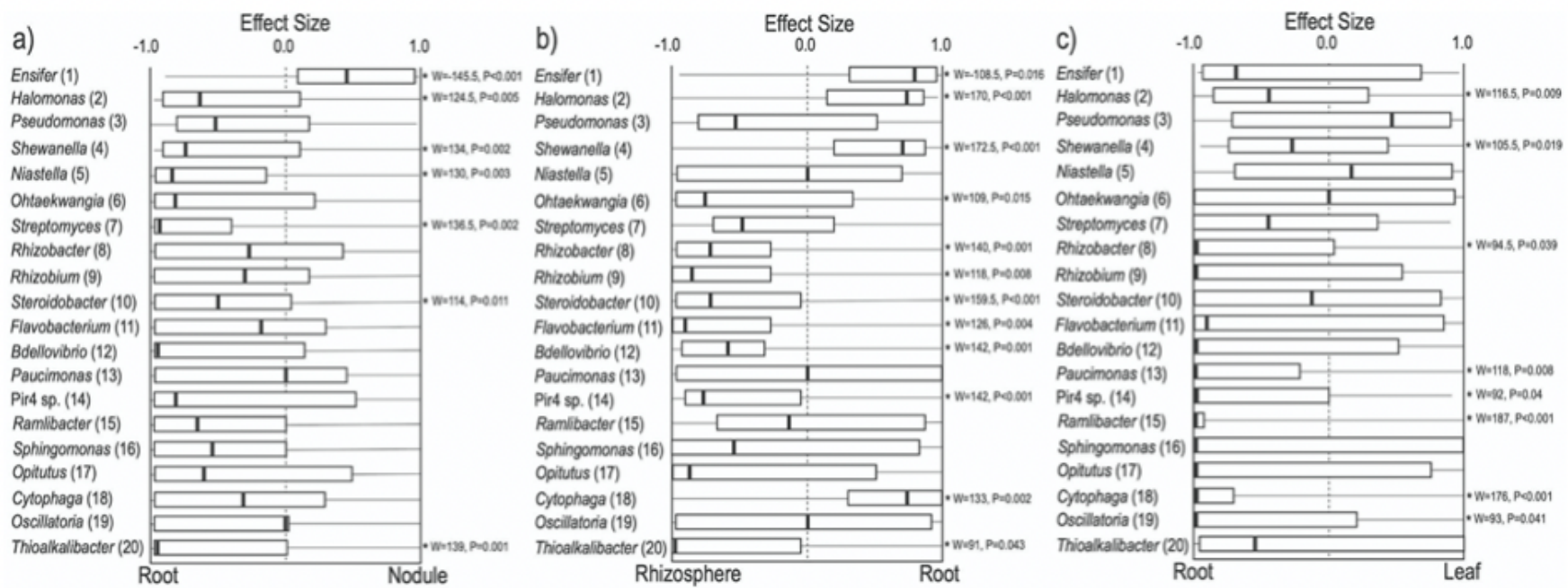

\section{Figure 3}

Paired effect size analysis of the 20 most abundant OTUs comparing relative abundances of each OTU within the same plant between Root and Nodule (a), Rhizosphere and Root (b), and Root and Leaf (c) compartments. Bacterial genera are on the left and OTUs number presented parenthetically. Presented are Quintiles (Minimum, 25\%, Median, 75\%, Maximum) of paired effect size [e.g. Nodule-Root/(Nodule+Root)] where a value of 1.0 indicates this OTU is only found in the nodules where as a value of -1.0 means the genus was only found in the Root. Tests for significant enrichment of OTUs between compartments using Wilcoxon Sign-Rank tests are presented where significant and indicated with tests statistics and p-values. 


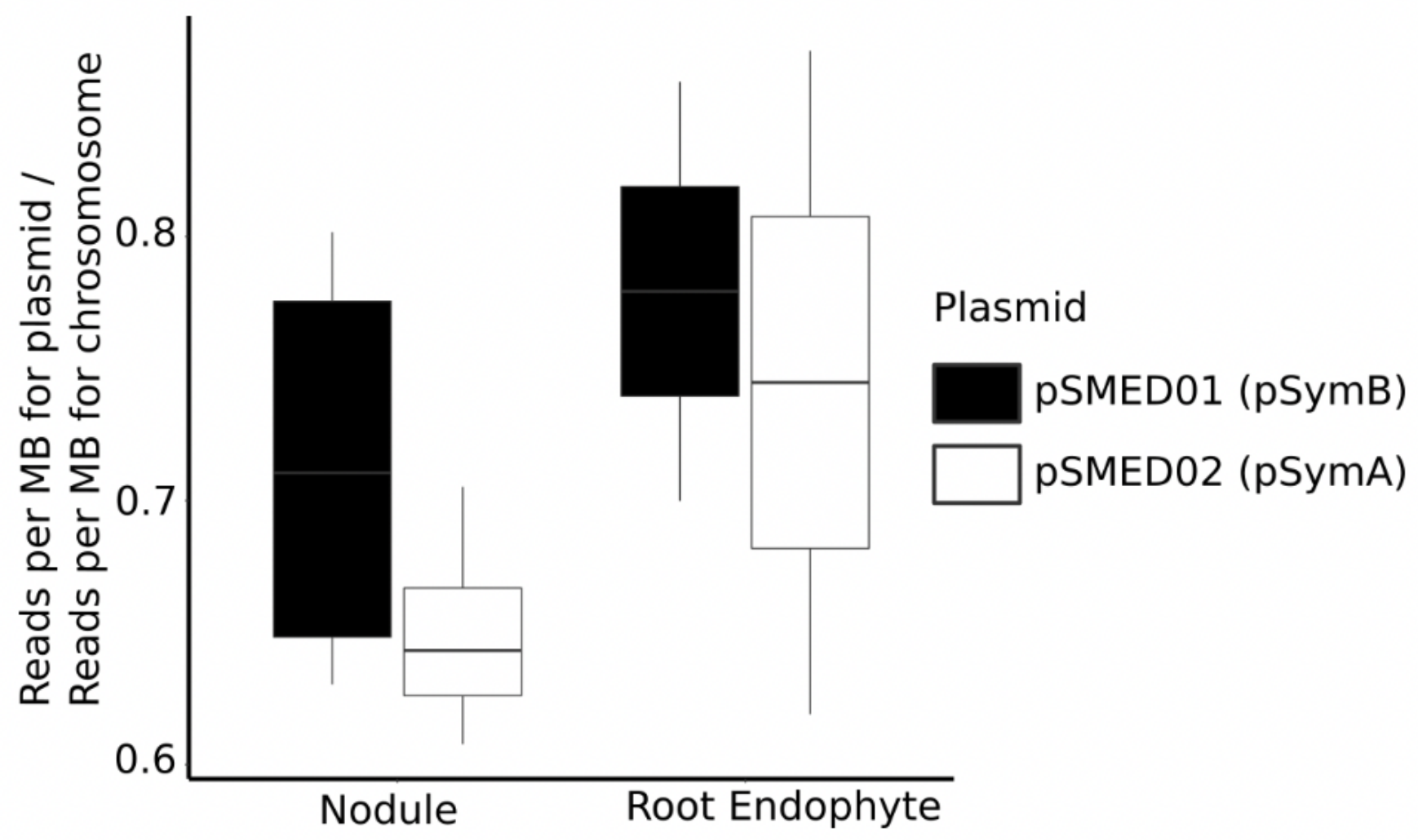

Figure 4

Genomic content of Ensifer from root versus nodule endosphere compartments from shotgun metagenomic sequencing data, shown as the median proportion of reads mapping to the symbiotic plasmid (pSymB in black, pSymA in white) relative to the chromosome. Lower and upper bounds of each box depict the first and third quartiles, respectively, with whiskers representing the range of observed values.

\section{Supplementary Files}

This is a list of supplementary files associated with this preprint. Click to download.

- AdditionalFile4FigureS4.pdf

- AdditionalFile8SupplementaryTextS1.pdf

- AdditionalFile9TableS6.xlsx

- AdditionalFile10TableS7.xIsx

- AdditionalFile2Tables2.xlsx

- AdditionalFile1TableS1.xlsx

- AdditionalFile7TableS5.xlsx 
- AdditionalFile6TableS4.docx

- AdditionalFile5TableS3.xlsx

- AdditionalFile3FigureS1.pdf 